\title{
AT-TAFRTER
}

VOLUME 14 NOMOR 1 TAHUN 2021

10.32505/at.vl4i2.3431

\section{Historis Periodesasi Perkembangan Hadis dari Masa ke Masa (Rasulullah, Sahabat, Tabi'in)}

\author{
Zaenuri'; Rahmah Zaqiyatul Munawaroh ${ }^{2}$ \\ ${ }^{12}$ UIN Sunan Kalijaga Yogyakarta \\ nurizae07@gmail.com ${ }^{1}$, zmmunawaroh@gmail.com²
}

\begin{abstract}
In the study of this discussion, the author explains the history of the development and codification of hadith from the time of the prophet, the companions and the tabi'in. things like this are certainly very important and basic before studying more broadly about hadith. The urgency of the purpose of this discussion is to study the history of hadith from time to time. This paper is expected to be an entry point in studying other hadith sciences, both in terms of their distribution, as seen from the number of narrators of their quality. The type of research method used in this research is a study of literature or literature with a descriptive qualitative approach. The result of this discussion is the development of hadith at this time, the Muslim community still does not understand hadith or write hadith. At this time the prophet always emphasized to his companions to understand the hadith and convey it to Muslims. The companies themselves are considered to have received a lot of hadith and some are also few due to factors of residence, area, age and so on. One of the greatest policies of the prophet regarding the maintenance of both of them was to command the companions to memorize and write the Qur'an, and officially appointed a revelation writer who was in charge of recording every verse of the Qur'an that was revealed under the direct instructions of the Prophet SAW. Many of the property's traditions, so the tabi'in, who are the companions' disciples, also collect a lot of the prophet's hadiths and even this collection is arranged in an orderly manner. The method used by the tabi'in in collecting and recording hadith is through meetings (al-talaqqi) with their friends and then the record what they get from the meeting.
\end{abstract}

Keywords: Hadith, Prophet Muhammad, Companions

Abstrak: Dalam kajian pembahasan ini, penulis menjelaskan terkait sejarah perkembangan dan kodifikasi hadis dari masa Rasulullah, Sahabat dan Tabi'in. hal yang seperti ini tentunya sangatlah penting dan mendasar sebelum mengkaji lebih luas tentang hadis. Urgensi ataupun tujuan dari pembahasan ini yaitu untuk mempelajari sejarah hadis dari masa ke masa., Tulisan ini diharapkan dapat menjadi pintu masuk dalam mengkaji perihal ilmu-ilmu hadis lainya, baik pembagianya, yang dilihat dari kuantitas periwayat atau kualitasnya. Jenis metode penelitian yang digunakan dalam penelitian ini adalah studi kepustakaan atau literatur dengan pendekatan kualitatif deskriptif. Hasil dari pembahasan ini yaitu perkembangan hadis pada masa ini masyarakat umat Islam masih terbilang kurang memahami hadis maupun menulis hadis. Pada masa ini Rasulullah selalu menekankan kepada sahabat agar selalu memahami hadis dan menyampaikanya 
kepada umat Islam. Para sahabat sendiri terbilang ada yang banyak menerima hadis dan juga ada yang sedikit dikarenakan faktor tempat tinggal, daerah, usia dan sebagainya. Salah satu kebijakan terbesar Nabi terkait pemeliharaan kedunya adalah dengan memerintahkan para shahabat untuk menghafal dan menulis AlQur'an, serta secara resmi mengangkat penulis wahyu yang bertugas mencatat setiap ayat al-Qur'an yang turun atas petunjuk langsung dari Nabi SAW. Para sahabat Nabi sudah banyak yang mengoleksi hadis-hadis Nabi, maka para tabi;in yang notabenya para murid sahabat juga banyak mengoleksi hadis-hadis Nabi bahkan pengoleksian ini disusun suatu kita yang beraturan. Metode yang dilakukan para tabi'in dalam mengoleksi dan mencatat hadis adalah melalui pertemuan-pertemuan (al-talaqqi) dengan para sahabat selanjutnya mereka mencatat apa yang didapat dari pertemuan tersebut.

Kata kunci: Hadis, Rasulullah, Sabatat dan Tabi'in

\section{PENDAHULUAN}

Umat Islam percaya bahwa hadis adalah sumber hukum kedua dalam Islam setelah Al-Qur'an. Meskipun secara historis hadis adalah sebuah rekam jejak sejarah Nabi yang erat kaitanya dengan peradaban sejarah Nabi yang erat kaitanya dengan peradaban Arab awal (sering juga disebut sunnah), tetapi pada sisi berbeda hadis telah menjadi bagian dari kehidupan Nabi yang bersumber dari Al-Qur'an sehingga tidak dapat dipungkiri ketika Isti Nabi mengatakan bahwa Nabi adalah Al-Qur'an yang hidup, sebab semua yang terkait dengan Nabi dari ucapan, perilaku, dan ketetapan mengejawantakan nilai-nilai Al-Qur'an (Muhtador t.t., 259).

Hadis merupakan sumber ajaran Islam kedua setelah Al-Qur'an. Istilah hadis biasanya mengacu pada segala sesuatu yang terjadi sebelum maupun setelah kenabianya. Termasuk hadis terkadang dipertukarkan dengan istilah tersebut adalah sinonim (mutaradif), sementara sebagian yang lainya ada yang membedakan antara keduanya. Sejarah dan perkembangan hadis dapat dilihat dari dua aspek penting, yaitu periwayatan dan pembawaanya. Dari keduanya dapat diketahui proses dan transformasi yang berkaitan dengan perkataan, perbuatan, hal ihwal, sifat dan taqrir dari Nabi SAW kepada para sahabat dan seterusnya hingga munculnya kitab-kitab himpunan hadis untuk dijadikan pedoman dalam kehidupan ini. Terkait dengan masa pertumbuhan dan perkembangan hadis, para ulama berbeda dalam menyusunya. (Leni Andariati, 2020:154).

Hadist-hadist atau sunah Rasulullah SAW merupakan pedoman kedua bagi umat Islam setelah Al-Qur'an. Kehidupan umat Islam tidak dilepaskan dari peran hadis, seperti halnya Al-Qur'an. Karena dari dengan bantuan hadis-hadis Rasulullah SAW umat Islam dapat memahami kandungan Al-Qur'an. Disamping hadis juga sumber utama bagi perkara-perkara yang tidak didapat didalam AlQur'an. Hadis yang sampai kepada kita saat dalam bentuk kitab-kitab yang sudah 
tercetak. Baik kutub as-sittah, ktub at-tis'ah, atau kitab-kitab hadis lainya yang berjumlah ratusan telah melewati proses dalam waktu yang lama dan seleksi yang ketat. Sejak masa Rasulullah SAW masih hidup, penulisan hadis sudah mulai diperbincangkan. Adanya hadis-hadis yang melarang dan membolehkan menulis hadis memicu perbedaan dikalangan umat Islam, dilanjutkan dengan sikap keras para sahabat setelah wafatnya Rasulullah SAW dalam periwayatan hadis juga membuat perkembangan hadis semakin hangat untuk diungkap. (Muhammad Iskandar, 2020:53).

Para sahabat Rasul adalah orang Arab tulen yang mayoritas tidak bisa baca tulis, namun demikian mereka mempunyai kemampuan hafalan yang luar biasa. Semenjak jaman jahiliyah mereka biasa menghafal nasab/ garis keturunan sampai nenek moyang mereka, riwayat-riwayat tentang kejadian yang mereka alami, dan bahkan mereka pun hafal syair-syair dan khitabah-khitabah yang pernah diucapkan. Dengan kekuatan hafalan bangsa Arab yang sedemikian rupa itu, seolah-olah Allah telah mempersiapkan mereka untuk mendukung datangnya kenabian Muhammad SAW. Disamping itu ayat-ayat Al-Qur'an sendiri banyak memerintahkan umat Islam, dalam hal ini para sahabat. Untuk mentaati dan mengikuti Rasul sampai kepada segala pola perilaku keseharianya, karena Rasul adalah orang-orang yang benar mempunyai akhlak yang luhur. Dan menjadi suri tauladan umatnya. Dan tidak hanya sampai disitu Al-Qur'an pun memerintahkan umat Islam membedakan orang yang berilmu dan yang tidak berilmu, yaitu dengan

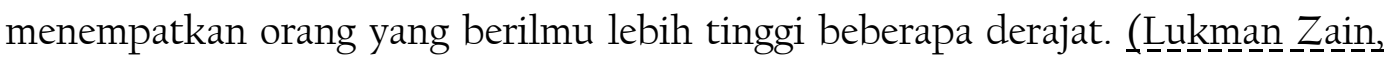
2014ㄴ.2).

Sepeninggal Nabi Muhammad SAW, kalangan sahabat sangat berhati-hati dalam menerima dan meriwayatkan hadis. Hal ini dimaksudkan sebagai upaya menjaga kemurnian Al-Qur'an agar tidak tercampur dengan hadis. Selain itu juga untuk menjaga keorisinalitas hadis tersebut. Keadaan ini diera tabi'in sedikit berbeda dengan era yang terjadi masa sahabat. Karena Al-Qur'an ketika itu telah disebarluaskan ke seluruh Negeri Islam, sehingga tabi'in bisa mulai memfokuskan diri dalam mempelajari hadis dari para sahabat yang mulai memfokuskan diri dalam mempelajari hadis dari para sahabat yang dimulai bersebaran ke seluruh penjuru dunia Islam. Dengan demikian pada masa tabi'in sudah mulai berkembang perhimpunan hadis, meskipun masih ada percampuran antara hadis Nabi dengan fatwa sahabat. Barulah diera tabi'in hadis telah dibukukan, bahkan diera ini menjadi masa kejayaan kodifikasi hadis (Leni Andariati, 2020:154).

Hadis memiliki kisah tersendiri mulai dari penjagaan pada masa Rasulullah masih hidup sampai masa penkodifikasianya secara resmi yang terjadi pada masa pemerintahan Khalifah Umar bin Abdul Aziz pada tahun 99-101 H. kodifikasi bermakna menyusun, membukukan, mencatat peraturan menjadi buku undangundang. Didalam Islam telah terjadi dua kodifikasi hadis yang sangat penting. Yaitu kodifikasi Al-Qur'an yang terjadi pada masa pemerintahan Khalifah Abu 
Bakar ash-Shiddiq dan kodifikasi hadis pada masa pemerintahan Khalifah Umar bin Abdul Aziz. Kodifikasi Al-Qur'an dilatarbelakangi faktor-faktor tertentu. Kodifikasi Al-Qur'an dilator belakangi kekhawatiran akan hilangnya Al-Qur'an karena banyak para penghafal Al-Qur'an dalam peperangan. Adapun kodifikasi hadisdiantaranya dilatar belakangi dengan banyak-banyaknya hadis palsu. Karena hakekatnya dalam proses mengumpulkan hadis, seorang muhaddis mengerahkan segala daya upaya untuk melakukan kajian-kajian hadis dari sisa sanad dan matan sebelum akhirnya dicantumkan dalam sebuah kitab (Muhammad Iskandar, 2020:53).

Dari segi periwayatan, kodifikasi hadis merupakan problem dan perhatian yang lebih banyak dari Al-Qur'an, hal tersebut sangat terlihat dari kondisi periwayatanya yang awalnya hanya berupa tradisi lisan dengan sebaran yang sangat sedikit. Setelah Nabi Muhammad SAW wafat muncul berbagai problematika yang mendasar ditengah komunitas Islam awal yang ikut andil dalam penyelesaian kegelisahan umat. Pada saat itu Umar bin Khattab menawarkan rencana untuk mengkodifikasikan Al-Qur'an diabadikan dengan hafalan yang kuat serta masalah pribadi dari para sahabat, dan dengan melalui usaha Usman bin Affan beberapa konflik yang tumbuh dalam umat Islam saat itu dapat terselesaikan dengan proyek penyatuan dalam Al-Qur'an dalam sebuah mushaf yang dikenal dengan sebutan mushaf utsmani. Selanjutnya jika proses kodifikasi hadis, dimana sebagian besarnya tergantung pada kekuatan daya hafalan dari para sahabat serta memarginalkan peran budaya tulis menulis untuk merekam segala sesuatu yang bersumber dari Nabi Muhammad SAW baik berupa ucapan, sifat, serta, tindakan pernyataan beliau (RiskaYunitasari, 2020: 102).

Dalam penelitian sebelumnya, penelitian yang dilakukan oleh Juliaanto Andrea yang berjudul "Hadis Pada Masa Nabi Muhammad Dan Di Era Kodifikasi Hadis, menunjukkan bahwa bahasan ini ialah hadis pada masa Nabi Muhammad SAW dan diera kodifikasi hadis adalah suatu yang sangat penting dalam menunjukkan kajian ulumul hadis. Hal ini dikarenakan hadis merupakan suatu penjelasan ayat Al-Qur'an yang diturunkan oleh Allah melalui malaikat untuk disampaikan kepada Nabi Muhammad Saw secara bertahap. Diketahui bahwa tulisan ini mengeksplorasi didalamnya adalah (1) hadis masa Rasulullah (2) hadis pada masa sahabat (3) hadis pada masa tabi'in. sebelum mempelajari sejarah pertumbuhan hadis diharapkan dapat mengetahui suatu Tindakan umat Islam terhadap hadis serta usaha yang dilakukanya dapat memelihara disetiap periode hadis hingga akhirnya muncul kitab-kitab secara sempurna yang dalam Islam dikenal dengan tadwin. Banyak sejarah yang memang dijalani mulai masa Rasulullah sampai masa ini atau masa sebelum pembukuan, karena perjalanan ini sangat panjang jika dilihat dan dibaca sejarahnya, perjuanganya tidak mudah sangat berliku sebenarnya. 
Dalam kajian pembahasan ini, penulis menjelaskan terkait sejarah perkembangan dan kodifikasi hadis dari masa Rasulullah, Sahabat dan Tabi'in. hal yang seperti ini tentunya sangatlah penting dan mendasar sebelum mengkaji lebih luas tentang hadis. Kemudian urgensi ataupun tujuan dari pembahasan ini yaitu untuk mempelajari sejarah hadis dari masa ke masa. Hal ini dapat membantu dalam mengetahui proses pertumbuhan dan perkembangan hadis dari masa ke masa yang begitu dinamis dan kompleks. Lebih lanjut lagi jika dikaji dengan seksama situasi dan keadaan sejarah perjalanan dan perkembangan hadis mulai dari pertumbuhanya hingga sekarang. Dengan kajian ini, tulisan ini diharapkan dapat menjadi pintu masuk dalam mengkaji perihal ilmu-ilmu hadis lainya, baik pembagianya, yang dilihat dari kuantitas periwayat atau kualitasnya.

\section{METODE PENELITIAN}

Jenis metode penelitian yang digunakan dalam penelitian ini adalah studi kepustakaan atau literatur dengan pendekatan kualitatif deskriptif. Menurut Sugiyono, data kualitatif adalah data yang dinyatakan dalam bentuk kalimat, kata dan gambar. Jenis penelitian deskriptif yang digunakan adalah studi pustaka. Sumber data yang digunakan adalah studi kepustakaan dengan mencari sumber data baik berupa, artikel, buku jurnal ilmiah yang berkaitan dengan penelitian sebelumnya yang relevan. Teknik pengumpulan data yang digunakan adalah observasi, kepustakaan, bahan yang akan diobservasi dalam penelitian ini adalah artikel jurnal yang berkaitan dengan sejarah dan kodifikasi hadis dari masa Rasulullah, Sahabat dan Tabi'in.

\section{HASIL DAN PEMBAHASAN}

\section{Historis hadis pada masa Rasulullah SAW}

Pada masa kepemimpinan Nabi, kecakapan dalam baca tulis masih terbilang sangat kurang, maka Nabi menekankan para shahabat untuk menghafal Hadist, memahami, memelihara, dan memantapkannya dalam bentuk amalan sehari-hari, serta menyampaikanya kepada orang lain (Endang Soetari, 2008:54). Masa ini berlangsung selama 23 tahun, mulai tahun 13 sebelum Hijriyah, bertepatan dengan tahun 610 Masehi sampai dengan tahun 11 Hijriyah, bertepatan dengan tahun 632 Masehi (Latifah Anwar, 2020:132). Menurut Abd al-Nashr, Allah telah memberikan keistimewaaan kepada para sahabat kekuatan daya ingat dan kemampuan menghafal. Mereka dapat meriwayatkan al-Qureean, hadis dan syair dengan baik seakan-akan mereka membaca dari sebuah buku (Latifah Anwar, 2020:133).

Para shahabat tidak sederajat dalam mengetahui keadaan Nabi SAW. Ada sahabat yang menerima banyak Hadist, ada pula yang sedikit, hal ini dipengaruhi oleh faktor tempat tinggal, pekerjaan, usia, dan lainnya. Ada shahabat yang tinggal di kota, di dusun, berniaga, bertukang, dll. Nabi pun tidak selalu mengadakan 
ceramah terbuka. Ceramah terbuka diberikan beliau hanya tiap hari Jum'at, hari raya dan waktu-waktu yang tidak ditentukan, jika keadaan menghendaki ( (AshShiddieqy, 2019, 30). Salah satu kebijakan terbesar Nabi terkait pemeliharaan kedunya adalah dengan memerintahkan para shahabat untuk menghafal dan menulis Al-Qur'an, serta secara resmi mengangkat penulis wahyu yang bertugas mencatat setiap ayat al-Qur'an yang turun atas petunjuk langsung dari Nabi SAW. Nabi juga memerintahkan shahabat untuk menghafal dan ditablighkan dengan tidak boleh mengubahnya sama sekali, dan tidak melakukan penulisan Hadist secara resmi seperti al-Qur'an (Soetari, 2008, 35).

Dari keterangan di atas bahwasanya, perkembangan hadis pada masa ini masyarakat umat Islam masih terbilang kurang memahami hadis maupun menulis hadis. Pada masa ini Rasulullah selalu menekankan kepada sahabat agar selalu memahami hadis dan menyampaikanya kepada umat Islam. Para sahabat sendiri terbilang ada yang banyak menerima hadis dan juga ada yang sedikit dikarenakan faktor tempat tinggal, daerah, usia dan sebagainya. Salah satu kebijakan terbesar Nabi terkait pemeliharaan kedunya adalah dengan memerintahkan para shahabat untuk menghafal dan menulis Al-Qur'an, serta secara resmi mengangkat penulis wahyu yang bertugas mencatat setiap ayat al-Qur'an yang turun atas petunjuk langsung dari Nabi SAW.

\section{Penulisan Hadis Pada Masa Sahabat}

Setelah Rasulullah SAW Wafat, para sahabat sebenarnya tidak kesulitan dalam mencari-cari hadis Rasulullah karena masih segar dalam ingatan mereka tentang kebersamaan mereka bersama Rasululullah SAW. Akan tetapi kekhawatiran para sahabat akan terjadinya kedustaan terhadap Rasulullah SAW membuat mereka sangat berhati-hati dalam menerima hadis-hadis walaupun dari kalangan sahabat sendiri. Hal ini dikarenakan sabda Rasullulah SAW yang diriwayatkan oleh Abu Hurairah:

$$
\text { النهاير ن ا يم ادهُ امقُعا هو أُ با تا لْيا فا ادا، مِ عاي مُتاي هـ عالا ب ا اذ ك ا امنْ }
$$

"Barang siapa berdusta atas namaku dengan sengaja, maka hendaklah menempati tempat dineraka" (HR. Muslim).

\section{Abu Bakar al-Siddiq}

Menurut Muhammad al-Dzahabi, Abu Bakar merupakan sahabat Nabi yang pertama-tama menunjukkan kehati-hatianya dalam periwayatan hadis. Pernyataan ini didasarkan atas pengalaman Abu Bakar tatkala menghadapi kasus waris untuk seorang nenek. Suatu ketika ada seorang nenek menghadap khalifah Abu Bakar menjawab bahwa, dia tidak melihat petunjuk Al-Qur'an dan praktek Nabi yang memberi bagaian harta kepada seorang nenek. Abu bakar lalu bertanya 
kepada para sahabat, Al-Mughirah ibn Syu'bah menyatakan kepada Abu Bakar, bahwa Nabi telah memberikan harta bagian waris kepada nenek sebesar seperenam bagian. Mendengar pernytaan tersebut, abu bakar meminta agar al-

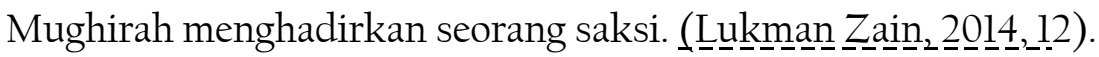

\section{Umar Ibn al-Khattab}

Umar juga dikenal sebagai sahabat yang sangat berhati-hati dalam periwayatan hadis, seperti halnya Abu Bakar. Selain itu Umar juga menekankan kepada para sahabat agar tidak memperbanyak periwayatan hadis dimasyarakat, dengan alasan supaya konsentrasi dimasyarakat tidak terpecah dalam membaca dan mendalami Al-Qur'an, selain itu juga supaya umat Islam tidak melakukan kekeliruan dalam periwayatan hadis. Kebijaksanaa Umar inilah yang kemudian mampu menghargai orang-orang yang tidak bertanggung jawab untuk melakukan pemalsuan-pemalsuan hadis (Andariati, 2020, 158).

\section{Usman Ibn Affan}

Secara umum, kebijakan Usman tentang periwayatan hadis tidak jauh berbeda dengan apa yang telah ditempuh oleh kedua Khalifah pendahulunya. Hanya saja, langkah Usman tidaklah setegas langkah Umar al-Khattab. Dalam suatu kesempatan Khutbah, Usman meminta kepada para sahabat agar tidak banyak meriwayatkan hadis yang mereka tidak pernah mendengar hadis itu pada masa Abu Bakar dan Umar. Pernyataan Usman ini menunjukkan pengakuan Usman atas sikap hati-hati kedua khalifah pendahulunya. Sikap hati-hati ini akan

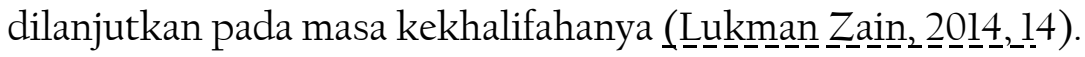

\section{Ali Abi Thalib}

Khalifah Ali Ibn Abi Thalib pun tidak jauh berbeda sikapnya dengan para khalifah pendahulunuya dalam periwayatan hadis. Secara umum, Ali barulah bersedia menerima riwayat hadis setelah periwayat hadis yang bersangkutan mengucapkan sumpah, bahwa hadis yang disampaikanya itu benar-benar berasal dari Nabi. Hanyalah terhadap periwayat yang benar-benar dipercayainya. Ali tidak meminta periwayat hadis untuk bersumpah. Hal ini terlihat misalnya ketika Ali menerima riwayat Abu Bakar al-Shiddiq terhadap Abu Bakar, Ali tidak memintanya untuk bersumpah. Dalam suatu riwayat, Ali menyatakan, "Abu Bakar

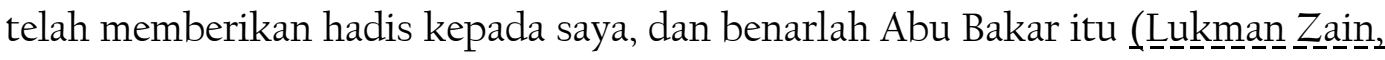
201는 15$)$.

Dari keterangan diatas terkait hadis pada masa sahabat bahwasanya Kebenaran suatu hadis harus diteliti secara cermat karena kedudukan hadis demikian tinggi, yakni sebagai sumber ajaran Islam yang kedua setelah Al-Qur'an. Adanya kekhalifahan, atau bahkan kesengajaan memalsukan hadis, merupakan hal menyadari akan kemungkinan itu. pada masa Abu Bakar As-shidiq suatu informasi 
itu harus adanya seorang saksi, kemudian pada masa Umar juga menekankan kepada para sahabat agar tidak memperbanyak periwayatan hadis dimasyarakat, agar tidak terpecah belah dalam memaknai Al-Qur'an dan hadis. Selanjutnya pada masa Usman Dalam suatu kesempatan Khutbah, Usman meminta kepada para sahabat agar tidak banyak meriwayatkan hadis yang mereka tidak pernah mendengar hadis itu pada masa Abu Bakar dan Umar. Dan yang terakhir pada masa Ali Abi Thalib bersedia menerima riwayat hadis setelah periwayat hadis yang bersangkutan mengucapkan sumpah, bahwa hadis yang disampaikanya itu benarbenar berasal dari Nabi

\section{Hadis Pada Masa Tabi'in}

Selain para sahabat yang sudah banyak mengoleksi hadis Nabi, ada juga memang dari kalangan para tabi'in yang notebenya adalah para murid sahabat juga banyak yang mengoleksi hadis-hadis Nabi, bahkan pula mereka mengoleksinya sudah mulai disusun dalam sebuah kitab yang beraturan. Sebagaimana pula sahabat, para tabi'in pun sama sangat berhati-hati dalam meriwayatkan hadis. Hanya saja mungkin pasti ada perbedaanya ialah dari segi beban yang dihadapi oleh sahabat dan tabi'in, dan tentu beban sahabat lebih berat jika dibandingkan oleh tabi'in. karena dimasa tabi'in Al-Qur'an telah dikumpulkan dalam satu mushaf, selain pula pada masa akhir periode Khulafaurasyidin (terkusus pada masa Usman bin Affan), para sahabat ahli hadis telah menyebar diberbagai Negara Islam (Julianto Andrea, 2020, 52).

Dari keterangan diatas Jika para sahabat Nabi sudah banyak yang mengoleksi hadis-hadis Nabi, maka para tabi;in yang notabenya para murid sahabat juga banyak mengoleksi hadis-hadis Nabi bahkan pengoleksian ini disusun suatu kita yang beraturan. Metode yang dilakukan para tabi'in dalam mengoleksi dan mencatat hadis adalah melalui pertemuan-pertemuan (al-talaqqi) dengan para sahabat selanjutnya mereka mencatat apa yang didapat dari pertemuan tersebut. Seperti yang dilakukan Said bin al-Jabir yang mencatat hadishadis dari talaqqinya Said bin al-Musayyab, Hamman bin al-Munabbih hasil

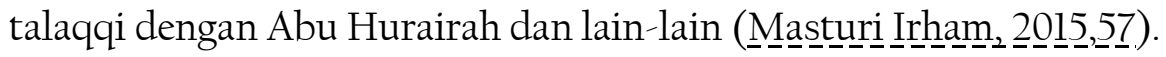

\section{KESIMPULAN}

Hadis merupakan sumber ajaran Islam kedua setelah Al-Qur'an. Istilah hadis biasanya mengacu pada segala sesuatu yang terjadi sebelum maupun setelah kenabianya. Termasuk hadis terkadang dipertukarkan dengan istilah tersebut adalah sinonim (mutaradif), sementara sebagian yang lainya ada yang membedakan antara keduanya. perkembangan hadis pada masa ini masyarakat umat Islam masih terbilang kurang memahami hadis maupun menulis hadis. Pada masa ini Rasulullah selalu menekankan kepada sahabat agar selalu memahami 
hadis dan menyampaikanya kepada umat Islam. Para sahabat sendiri terbilang ada yang banyak menerima hadis dan juga ada yang sedikit dikarenakan faktor tempat tinggal, daerah, usia dan sebagainya. Salah satu kebijakan terbesar Nabi terkait pemeliharaan kedunya adalah dengan memerintahkan para shahabat untuk menghafal dan menulis Al-Qur'an, serta secara resmi mengangkat penulis wahyu yang bertugas mencatat setiap ayat al-Qur'an yang turun atas petunjuk langsung dari Nabi SAW.

Para sahabat Nabi sudah banyak yang mengoleksi hadis-hadis Nabi, maka para tabi;in yang notabenya para murid sahabat juga banyak mengoleksi hadishadis Nabi bahkan pengoleksian ini disusun suatu kita yang beraturan. Metode yang dilakukan para tabi'in dalam mengoleksi dan mencatat hadis adalah melalui pertemuan-pertemuan (al-talaqqi) dengan para sahabat selanjutnya mereka mencatat apa yang didapat dari pertemuan tersebut. Seperti yang dilakukan Said bin al-Jabir yang mencatat hadis-hadis dari talaqqinya Said bin al-Musayyab, Hamman bin al-Munabbih hasil talaqqi dengan Abu Hurairah dan lain-lain.

\section{DAFTAR PUSTAKA}

Abduh, Muhammad. 2015. "Melacak Akar Kesejarahan Hadis Nabi PraKodifikasi” 6: 20 .

Andariati, Leni. 2020. "Hadis dan Sejarah Perkembangannya." Diroyah: Jurnal Studi Ilmu Hadis 4 (2): 153-66.

Andrea, Julianto. 2020. "Review Osf.Io Hadis Pada Masa Nabi Muhammad Dan Di Era Kodifikasi Hadis." OSF Preprints.

Anwar, Latifah. 2020. "Penulisan Hadis Pada Masa Rasulullah SAW." Al-Bayan: Jurnal Ilmu al-Qur'an dan Hadist 3 (2): 131-56.

Ash-Shiddieqy, Teungku Muhammad. 2019. Sejarah \& Pengantar Ilmu Hadist. 14 ed. Semarang: Pustaka Rizki Putra.

Damanik, Agusman. 2018. "Urgensi Studi Hadis Di UIN Sumatera Utara." SHAHIH (Jurnal Kewahyuan Islam) 1 (1).

Irham, Masturi. 2015. "Sistematika Kodifikasi Hadis Nabi Dari Tinjauan Sejarah." $A D D I N 7$ (2)

Iskandar, Muhammad. 2020. "Periodesasi Penulisan Hadis Nabi Saw." DIRAYAH: Jurnal Ilmu Hadis 1 (1): 52-67.

Muhtador, Mohammad. t.t. “Open Journal Systems.” Diakses 22 November 2021. 
Soetari, Endang. 2008. Ilmu Hadist Kajian Riwayah \& Dirayah. Kelima. Bandung: CV Mimbar Pustaka.

Yunitasari, Riska. 2020. "Masa Kodifikasi Hadis Meneropong Perkembangan Ilmu Hadis Pada Masa Pra-Kodifikasi Hingga Pasca Kodifikasi.” Ar-Risalah: Media KeIslaman, Pendidikan Dan Hukum Islam 18 (1): 101-13.

Zain, Lukman. 2014. "Sejarah Hadis Pada Masa Permulaan Dan Penghimpunannya." Diya Al-Afkar: Jurnal Studi al-Quran Dan al-Hadis 2 (01). 